\title{
Some orderly nonmonotonicities in the trial-by-trial acquisition of conditioned suppression: Inhibition with reinforcement?
}

\author{
JOHN J. B. AYRES, PAUL BERGER-GROSS, ELIZABETH A. KOHLER, \\ WILLIAM J. MAHONEY, and SANDY STONE \\ University of Massachusetts, Amherst, Massachusetts 01003
}

\begin{abstract}
The trial-by-trial acquisition of conditioned suppression was examined under a wide range of conditions. Frequently, the acquisition functions were nonmonotonic. In conditions containing four or more trials in sessions of $2 \mathrm{~h}$ or less, suppression, once established, tended to be significantly stronger on the first trial of a session than on one or more subsequent trials. The data from six conditions are presented to exemplify those under which nonmonotonicities did and did not occur. It is suggested that the nonmonotonicities are similar to effects described by Pavlov (1960, Lecture 14), effects which he believed reflected the growth of inhibition despite continuous reinforcement. Interpretations of the results in terms of reactive inhibition, short-term habituation, conditioned inhibition, inhibition of delay, and disinhibition are discussed.
\end{abstract}

When a stimulus previously paired with shock is: presented while animals perform some operant response for food reward, the usual result is a suppression of the response rate (Estes \& Skinner, 1941). In general, the degree of this "conditioned suppression" tends to increase monotonically over the first dozen or so trials, at which point suppression is usually asymptotic (e.g., Kamil, 1968; Kamin, 1969; Kamin \& Gaioni, 1974; Libby, 1951). Careful inspection of published trial-by-trial plots of the acquisition of suppression will often reveal one or two data points to be slightly "out of line" (e.g., Kamil, 1968; Kamin, 1969), but these departures from monotonicity are small and presumably due to random error. In fact, the just described acquisition functions are presumably obtained with such regularity that they are seldom of interest. They are rarely described in the conditioned suppression literature; and, when acquisition is described, the data are typically blocked across trials within a session, simply to save space, we surmise, and perhaps to smooth out the occasional wrinkles in the curves.

This work was supported by Grant BG-36982 from the National Science Foundation, Grant MH 28226-01 from the National Institute of Mental Health, Biomedical Sciences Support Grant RR07048 to the University of Massachusetts, and by grants from the Honors Office at the University of Massachusetts to Paul Berger-Gross and Sandra Stone. It was described at the November 1977 meeting of the Psychonomic Society, Washington, D.C. We thank Toni Alterman, Byron Farwell, and Bill Vallas for their assistance and Elizabeth S. Witcher for providing the data from Condition 3. We also thank L. J. Kamin for his comments on an earlier draft of the manuscript. Requests for reprints should be addressed to John J. B. Ayres, Psychology Department, Middlesex House, Amherst, Massachusetts 01003.
Given this background, we were surprised when, in the course of conducting a series of suppression experiments, we began to notice some curious nonmonotonicities in the trial-by-trial acquisition functions. At first we attributed these nonmonotonicities to random error. But as the data continued to mount, the nonmonotonicities persisted, and a consistent pattern began to emerge. One aim of the present paper is to describe this pattern and some conditions under which it does and does not occur. A second purpose is to try to decide whether this pattern is merely the result of a measurement artifact or, if not, what kinds of psychological processes it might reflect.

\section{METHOD}

\section{Subjects}

The subjects whose data were selected for presentation here were 140 male albino Sprague-Dawley rats from the Holtzman Company, Madison, Wisconsin; Camm Research Industries, Wayne, New Jersey; and Clinton Laboratories, Amherst, Massachusetts. Henceforth, they will be termed "Holtzman," "Camm," and "Clinton" rats, respectively. On arrival at the laboratory, they were housed in individual cages in a continuously illuminated room and were fed and watered freely until 1 week before training. They were then fed $3.5 \mathrm{~g}$ daily until they reached $80 \%$ of their freefeeding weights, at which they were maintained thenceforth. Water was always available in their home cages. Unless otherwise stated, all rats were approximately 100 days old at the start of training and were experimentally naive.

\section{Apparatus}

Eight Gerbrands operant conditioning chambers housed in ventilated $.61-\mathrm{m}$ cubes of $12.7-\mathrm{mm}$ plywood lined with acoustical tile were used in the conditions to be described. Each chamber had a $.1-\mathrm{ml}$ dipper feeder housed in a $5.5 \times 5.0 \times 5.0 \mathrm{~cm}$ receptacle 
mounted at floor level to the left of the standard Gerbrands bar. On the lid of each chamber were two $10-\mathrm{cm}$ speakers through which white noise or tonal stimuli could be presented. A $28-\mathrm{V}$ lamp was also mounted on the chamber lid and could be connected in parallel to a $28-\mathrm{V}$ cue lamp centered over the dipper receptacle and mounted $9.5 \mathrm{~cm}$ above the grid floor. Scrambled grid shock USs were provided by eight Grason-Stadler shock sources (Models E1064GS and 700 ). Presentation of stimuli and recording of responses was done with solid state and electromechanical switching circuitry housed in an adjoining room.

\section{Procedure}

The procedure in general was designed to establish a baseline rate of behavior, which could later be suppressed by CS presentations. In the conditions described, the baseline response was barpressing. Training, therefore, typically included magazine training, barpress shaping, continuous reinforcement, and finally some sessions in which responding was reinforced on VI 1- or 2-min schedules (Fleshler \& Hoffman, 1962). In all sessions, reinforcement for the baseline response was a $4-\mathrm{sec}$ presentation of the $.1-\mathrm{ml}$ dipper cup containing $32 \%(w / w)$ sucrose solution.

The trial-by-trial acquisition of conditioned suppression was then observed under a wide range of conditions. We shall describe six of these conditions. They can be grouped into three classes: (1) forward delay conditioning procedures with four to six daily trials given in sessions ranging in duration from $32 \mathrm{~min}$ to $2 \mathrm{~h}$ (Conditions 1 through 4); (2) a forward delay conditioning procedure with one daily trial in sessions of $15 \mathrm{~min}$ (Condition 5); and (3) a forward trace conditioning procedure with four daily trials in a 2 -h session (Condition 6). The procedural differences among these conditions were not created to test hypotheses about the phenomenon we shall describe, as the experiments were designed for other reasons entirely.

Condition 1. Thirty-six Holtzman rats, 85-90 days old, were magazine trained and then shaped to barpress. Each rat earned reinforcement for each of 90 responses in three shaping and continuous reinforcement sessions. In the next eight sessions, each $1 \mathrm{~h}$ long, barpressing was reinforced on a VI 2 -min schedule. In each of the last four of these sessions, four presentations of a 2-min $1,000-\mathrm{Hz}$ tone CS at $87-\mathrm{dB}$ intensity (re $20 \mu \mathrm{N} / \mathrm{m}^{2}$ ), were superimposed upon the barpress baseline. Intervals between successive $\mathrm{CS}$ onsets ranged from 7 to $19 \mathrm{~min}$. Each CS terminated with the onset of a 1-sec 1-mA scrambled grid shock US. Each box was illuminated by operating only the cue light on the front panel at $6 \mathrm{~V}$.

Condition 2. Sixteen Clinton rats received barpress shaping and continuous reinforcement as above, followed by 11 daily 1 -h sessions in which barpressing was reinforced on a VI 1-min schedule. In the last seven of these sessions, four 2 -min CSs coterminated with a 1-sec $1-\mathrm{mA}$ shock. The CS was intermittent white noise at $75-80 \mathrm{~dB}$; the on/off cycle for the noise was $1 \mathrm{sec}$ on/.11 sec off. Intertrial intervals were as before. Each box was totally dark.

Condition 3. Sixteen Holtzman rats received a 1-h magazine training session in which the bars were removed from the boxes and 4-sec presentations of sucrose were delivered at variable times averaging $1 \mathrm{~min}$ (VT 1-min schedule). The next day the bars were replaced and each barpress reinforced. Shaping was used if necessary until each rat had earned 50 reinforcers. Nine daily 2 -h sessions followed with a VI 2-min schedule of reinforcement in effect. In the initial session, however, a VI 1-min schedule prevailed for the first $20 \mathrm{~min}$. In the last four of these sessions, four 1-min CSs terminated with the onset of a $1-\mathrm{sec} 1-\mathrm{mA}$ shock. The CS was a $1 / \mathrm{sec}$ flashing of the cue light and roof light in synchrony. The flashing was created by switching the voltage across these lights from $26 \mathrm{~V}$ (the background condition) to $6.5 \mathrm{~V}$ once per second.

Condition 4. Thirty-two Camm rats received magazine training and shaping as in Condition 1, followed by nine daily 32-min sessions in which barpressing was reinforced on a VI 1 -min schedule. In each of the last five of these sessions, six 1-min presentations of a $1,000-\mathrm{Hz} .86-\mathrm{dB}$ tone coterminated with a $1-\mathrm{sec} .5-\mathrm{mA}$ shock. For 16 rats (Group C), the intershock interval was a constant
$5 \mathrm{~min}$. For the remaining 16 rats (Group V), the intershock interval was variable and averaged $5 \mathrm{~min}$. The boxes were constantly illu minated, but the usual "roof light" was removed from the chamber lid and mounted instead on the outside of the right-hand wall.

Condition 5. Sixteen Holtzman rats, some of which had previously been shaped to barpress for Noyes pellets in an undergraduate laboratory, received magazine training, shaping, and continuous reinforcement training as in Condition 1 . They then received five daily 15 -min sessions with a VI 1-min schedule of reinforcement in effect. Seven sessions followed in which a single 2 -min presentation of intermittent white noise ( $1 \mathrm{sec}$ on, $.11 \mathrm{sec}$ off) coterminated with a 1 -sec $1-\mathrm{mA}$ shock. Interpolated among these sessions for eight rats (Group R) were 12 "recovery" sessions in which respond. ing was reinforced on the VI schedule but no CSs or USs occurred. The exact order of conditioning $(C)$ and recovery sessions (R) was CRRRRCRRCRRCRRCRCRC. On recovery days, the remaining eight rats (Group $\mathrm{H}$ ) were merely weighed, returned to their home cages, and fed their daily rations.

Condition 6. Twenty-four Holtzman rats received (1) a magazine training session in which a 4-sec dipper presentation occurred at the end of each minute for a total of 60 presentations, (2) a barpress shaping session that ended when the rat had received reinforcement for each of 100 responses, (3) another session similarly terminated, and (4) 11 daily 2 -h sessions with responding reinforced on a VI 2-min schedule. In the last five of these sessions, a 2-sec presentation of an $81-\mathrm{dB} 1,000-\mathrm{Hz}$ tone was followed after an "empty trace" interval by the onset of a 1-sec 1-mA shock US. For different groups of eight rats each, the interval between CS onset and US onset was 62, 105, or $135 \mathrm{sec}$. Four such forward trace pairings were given to each group in each session. Suppression was measured in the $1-\min$ period prior to US onset.

\section{RESULTS}

Panels 1 through 6 of Figure 1 plot the trial-by-trial acquisition of conditioned suppression under Conditions 1 through 6 , respectively. The results are plotted in terms of the Annau-Kamin (1961) suppression ratio, $\mathrm{D} /(\mathrm{B}+\mathrm{D})$. Here $\mathrm{D}$ denotes the response rate

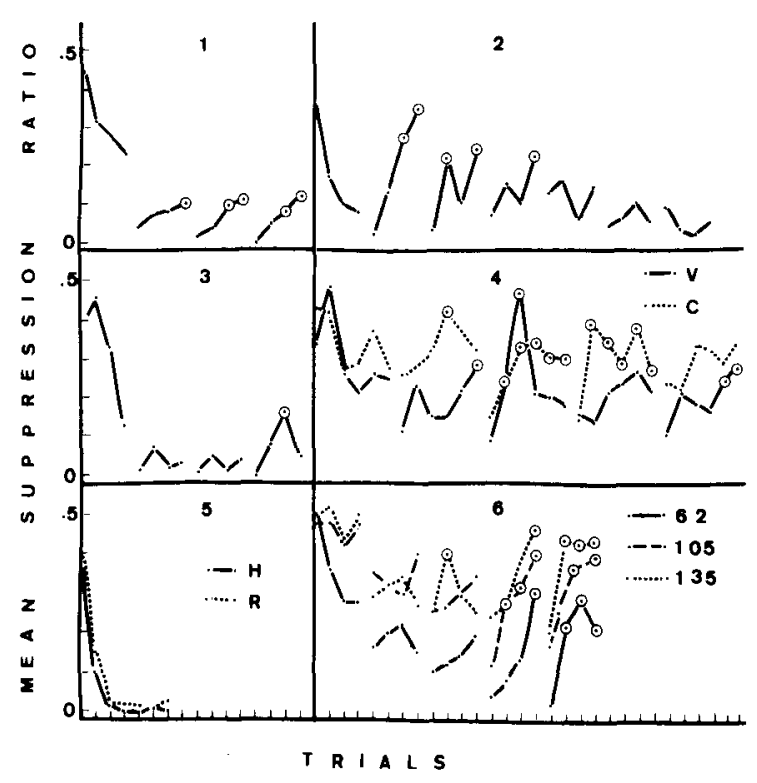

Figure 1. Acquisition of conditioned suppression in Conditions 1 through 6. The measure is the Annau-Kamin suppression ratio. 
during a CS presentation and $\mathrm{B}$ the rate in a baseline period, typically a period $10 \mathrm{sec}$ to $3 \mathrm{~min}$ before the CS. ${ }^{1}$ With this ratio, a score of 0 suggests strong suppression, while a score of .5 suggests no effect of the CS.

The results of Condition 1 clearly show the nature of the nonmonotonic acquisition functions we observed. Suppression increased across the four trials of the first session. In subsequent sessions, separated by breaks in the plot, suppression tended to be strongest on the first trial of the session and then weakened progressively across trials. On some of the later trials, indicated by circled data points, suppression was sig. nificantly weaker ( $p<.05$, two-tailed) than on the first trial of the session. ${ }^{2}$ The nonmonotonicities appear particularly orderly in Condition 1 probably because the plot is based on the average of 36 rats, an unusually large sample size in the conditioned suppression literature. It may be of interest to note, too, that the acquisition functions for 30 of these rats have been previously published (Ayres, Mahoney, Proulx, $\&$ Benedict, 1976, Figure 2, Panel A). At that time, we failed to notice the nonmonotonicities because, for the reasons given in the introduction, we blocked the data over trials within a session.

As shown in Panels 2, 3, 4, and 6, Conditions 2, 3, 4 , and 6 also produced nonmonotonic acquisition functions that shared some of the characteristics of those just described. Of special interest are the results of Condition 3. Here the procedures used were similar to those of Kamin (1969) and Kamin and Gaioni (1974), in which significant nonmonotonicities were presumably not observed. Our results look similar to theirs with only one exception: our data point at Trial 15 is significantly higher than that on Trial 13. Likewise, our one-trial-a-day procedure (Condition 5) was similar to that of Kamil (1968), and it is again reassuring that our results were similar to his. No significant nonmonotonicities were observed. (In the one-trial-a-day procedure, we defined a nonmonotonicity as a data point on one trial significantly higher than a point on any earlier trial.) It appears, then, that nonmonotonicities are rare or absent in two procedures that have become fairly standard in the suppression literature: the delay procedure with four trials per 2-h session (e.g., Panel 3, Figure 1, and Kamin, 1969) and the delay procedure with one trial a day (Figure 1, Panel 5, and Kamil, 1968). ${ }^{3}$ Nonmonotonicities appear more pronounced in delay procedures with four or more trials in a session of $1 \mathrm{~h}$ or less (Figure 1, Panels 1, 2, and 4). They are also pronounced in the trace procedure in which four trials occur in a 2-h session (Figure 1, Panel 6).

One possible interpretation of the nonmonotonicities just described is that they are simply a computational artifact caused by falling pre-CS rates across trials. Suppose, for example, that on the first trial of the 2 nd day of conditioning, a rat's pre-CS baseline rate was 10 responses/min. Assuming that suppression had been strongly conditioned on the 1st day, the rat's CS rate on the first trial of Day 2 might be some low value, say, 1 response/min. If the pre-CS rate were now to drop from 10 to 1 response/min across the remaining trials of the session, while the CS rate remained constant, then the suppression ratio would increase from .09 to .50 across these trials. Shown in Figure 2 are the mean pre-CS rates actually observed in all but Condition 1. (The pre-CS data for Condition 1 are no longer available.) It is clear that in Condition 2 the obtained pattern of falling pre-CS rates across trials within a session is very similar to the hypothetical pattern just described. This pattern, however, is less obvious in Conditions 3,4 , and 6 . In Condition 5, the pre-CS rates fell across trials for Group $\mathrm{H}$, which received home-cage sessions interpolated among conditioning sessions; however, the pre-CS rates remained high for Group $\mathbf{R}$, which received operant recovery sessions interpolated among conditioning sessions. Analysis of variance performed on the pre-CS data of this condition showed the Groups by Trials interaction to be reliable $[F(6,84)$ $=9.32, \mathrm{p}<.01]$.

One way to test the hypothesis that the nonmonotonicities are computational artifacts of falling pre-CS scores is to recompute all the suppression ratios, using as the baseline rate for each rat its pre-CS score on Trial 1 . Since this baseline rate would arbitrarily be the same for a given animal on every trial, rising suppression scores across trials could not possibly be computational artifacts of falling pre-CS rates.

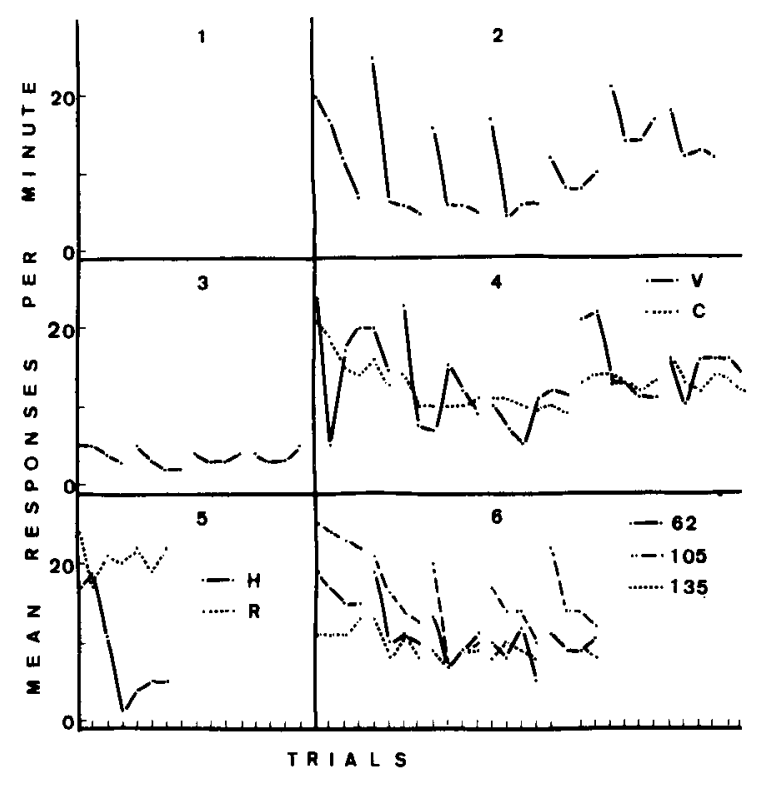

Figure 2. Pre-CS response rates during acquisition of conditioned suppression for Conditions 1 through 6. 
Instead, such rising ratios would have to reflect rising rates during the CS. These ratios, moreover, should, according to the work of Church (1969), be more sensitive to statistical analysis than an absolute measure of the CS rate.

Figure 3 replots the trial-by-trial acquisition functions of Figure 1 in terms of the suppression ratios just described. Clearly, this method of computing the ratio eliminated the nonmonotonicities in Conditions 2 and 3 . The phenomenon, however, was not eliminated in Conditions 4 and 6 . In the one-trial-a-day procedure, i.e., Condition 5, the new method of computing the suppression ratios had little effect at all; significant nonmonotonicities were again absent just as they were in the original plot (Figure 1).

The results of Conditions 4 and 6 seem to support the conclusion that declining pre-CS rates across trials are not necessary to produce the nonmonotonicities observed. The results of Group $\mathrm{H}$ in Condition 5 suggest that declining pre-CS rates are not sufficient to produce the effect. That is, the pre-CS rates declined systematically across trials for Group $H$ (Figure 2), yet significant nonmonotonicities did not occur (Figures 1 and 3). This conclusions, however, would appear to be on somewhat shakier ground, since there were only seven trials in this condition. With so few trials, there are obviously fewer opportunities to observe the nonmonotonic effects noted in the procedures involving four or more trials per day, given over 4 or more days. Although our results tentatively support the conclusion that declining pre-CS rates across trials are neither necessary nor sufficient for

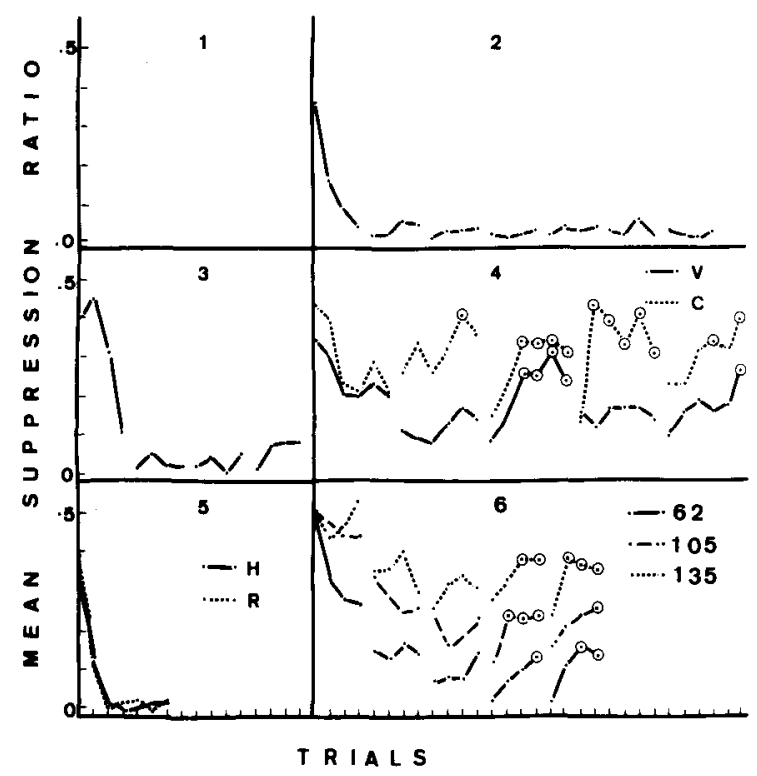

Figure 3. Acquisition of conditioned suppression in Conditions 1 through 6. The measure is a modified Annau-Kamin ratio in which each rat's Trial 1 pre-CS score was used as its pre-CS score on every trial. producing nonmonotonicities, they do not support the conclusion that such declining pre-CS rates are irrelevant. Certainly that conclusion would be hard to defend given the effects of recomputing the suppression ratio in Condition 2 .

In general, then, we found two kinds of treatments that seem to yield nonmonotonic acquisition functions which cannot be explained as artifacts of declining pre-CS rates. These treatments include the trace conditioning procedure (Condition 6) and the delay treatment (Condition 4) in which six trials were presented in a session of approximately $30 \mathrm{~min}$. These results are easily reproducible. In other work, which for the sake of brevity is not reported here, we have systematically replicated the trace conditioning results (Figure 3, Panel 6) using four trials per day in sessions of either 1 or $2 \mathrm{~h}$. We have also produced striking nonmonotonicities in the delay procedure (Figure 3, Panel 4) using four reinforced presentations of a $30-\mathrm{sec}$ noise CS in sessions of $26 \mathrm{~min}$.

\section{DISCUSSION}

The main finding of this research is that the functions describing the trial-by-trial acquisition of conditioned suppression over the first 20 or so trials are sometimes nonmonotonic. These nonmonotonicities are generated when several trials are given in each of several daily sessions and suppression on the first trial of a session is greater than that on one or more subsequent trials. In other words, the nonmonotonicities are due to within-session response decrementsdecrements in the strength of suppression across the several trials of a single session. In some cases, these decrements can be dismissed as computational artifacts due to falling pre-CS rates across trials within a session. In other cases, they cannot.

To the best of our knowledge, such within-session decrements have not been previously published in the conditioned suppression literature, although betweensession decrements have been described under prolonged acquisition conditions (Annau \& Kamin, 1961; Hendry \& Van-Toller, 1965; Millenson \& Dent, 1971; Zielinski, 1966).

Although we were initially surprised by the decrements we observed, we have since been reminded that within-session response decrements are an old phenomenon in the Pavlovian conditioning literature, having been described in detail by Pavlov (1960, Lecture 14) and also observed by early American workers in the field. [For a brief review of this literature, see Kimmel and Burns (1975). For more recent demonstrations with human eyelid and GSR conditioning, see Epstein and Bahm (1971) and Runquist and Muir (1965). For an extensive and critical discussion of postasymptotic performance decrements in general, see Prokasy (1960)]. 


\section{Some Possible Theoretical Accounts}

Short-term refractory processes. Hilgard and Marquis (1935) appear to have attributed the decrements they found in an eyelid conditioning situation to the growth of some short-term refractory-like process. They suggested that the "decremental factor is analogous to the effect of repetitive work" (p. 54). It appears, from this quotation, that Hilgard and Marquis had in mind a concept like Hull's $I_{R}$ (Hull, 1943), that is, a fatigue-like factor generated by evoking a CR. However, they may also have included within the concept of "repetitive work" the notions of CS habituation and/or US habituation. Indeed, the quotation above continues, "This suggestion is borne out by the fact that actual decrement within the day is found for unconditioned reflexes (negative adaptation), and for conditioned responses after they reach a sufficient magnitude"' (p. 54, italics added).

Taken alone, Hull's notion of reactive inhibition $\left(I_{R}\right)$ can account for many features of our findings. $I_{R}$ was said to build up over trials, to be greater with massed than with distributed trials, and to dissipate in time. Therefore, it explains the cumulative weakening across trials seen in Conditions 4 and 6 (Figure 3); it explains the "spontaneous recovery" of suppression on the first trial of the following session, and it explains why, under our delay conditioning procedures at least, the response decrements were greater with relatively massed practice (Condition 4 , Figure 3 ) than with more distributed practice (Conditions 2 and 3 , Figure 3). It also explains why there were no response decrements in the one-trial-a-day condition for Group R (Figure 3). There are, however, two problematic results for $I_{R}$ theory. One is the finding of response decrements in the trace conditioning procedure in which trials were widely spaced. This problem may be minimized by arguing that the stimuli present at the moment of US presentation were similar to those prevailing between trials; therefore, $I_{R}$ may have been maintained throughout the intertrial intervals rather than being allowed to dissipate. A second problem is the strong suppression evoked by the CS in Group $\mathrm{H}$ of the one-trial-a-day condition (Figure 3, Panel 5). The background cues for this group were presumably highly excitatory after several days of training; therefore, they should have evoked a CR for a long period prior to each CS. If evoking a CR engages an $I_{R}$-type mechanism, then we would expect a weak CR to the CS in Group H instead of the strong suppression actually obtained.

The notions of short-term CS and US habituation could also be applied to the present findings. Either phenomenon might explain why the $C R$ weakened within sessions and why, under the forward delay procedures, the decrements were greater with massed trials. Like the $I_{R}$ hypothesis, the CS-habituation hypothesis might account for the trace conditioning results by arguing that the stimuli most contiguous with US onset, i.e., the background cues, are present between trials. Habituation to these stimuli would thus occur during the intertrial intervals. The appeal of the CS-habituation hypothesis is further enhanced by recent evidence of Pfautz and Wagner (1976) that short-term CS habituation can produce response decrements during conditioning. Using an eyelid conditioning preparation in the rabbit, $\mathrm{Pfautz}$ and Wagner compared responding to an excitatory target CS when it was preceded by a recent presentation of (1) itself, (2) an excitatory stimulus in another modality, or (3) no stimulus. Relative to the case in which the target was not preceded by a stimulus, responding was depressed when the target was preceded by itself and enhanced when preceded by a CS in a different modality. This result is clearly inconsistent with an $I_{R}$ hypothesis and consistent with a CS-habituation hypothesis. Further, it suggests a simple technique for separating the role of CS habituation, US habituation, and $I_{R}$ in producing the decrements we have observed. If the type of CS (e.g., tone, light, noise) were varied from trial to trial in a forward delay procedure, only CS habituation should be reduced; US habituation and $I_{R}$ should remain roughly constant. Only the CS-habituation hypothesis, therefore, would predict a substantial reduction in the decrements relative to those obtained here.

Conditioned inhibition. Within-session decrements, followed by overnight recovery, might also be explained in terms of Hull's (1943) notion of conditioned inhibition (SIR). The following account of the phenomenon, quite similar to that offered by Pavlov (1960), is borrowed from an explanation Hull offered for the so-called "Switzer effect" (see Kimmel \& Burns, 1975). The Switzer effect refers to an increase in the strength of a CR over the first few trials of extinction. Hovland (1936) using the galvanic skin response, found the Switzer effect only when extinction immediately followed a massed acquisition series. Hull's (1943) account of this finding was as follows: "When conditioned reactions are set up by means of massed reinforcements, conditioned inhibition is generated which, at the outset of extinction, is disinhibited through the change in the functioning afferent impulses, with the result that the curve of experimental extinction shows an initial rise" (p. 293). Applied to the present results, this idea seems to hold that as $I_{R}$ is built up over a series of massed trials, SIR becomes conditioned to the CS, thus causing response decrements. On the following day, suppression is strong on the first trial because some of the stimuli controlling this conditioned inhibition, namely, the stimulus traces of preceding trials, have been removed. This hypothesis seems to be able to account for the same aspects of our data as does the $I_{R}$ concept and to be beset with the same problems. It is also 
less parsimonious, since it requires both the concepts of $I_{R}$ and $S I R$, plus the notion of disinhibition of SIR. It does seem to suggest at least one prediction not suggested by the concept of $I_{R}$ alone, i.e., that any within-session response decrements should be unique to the stimulus undergoing massed reinforcement. However, this same prediction could be derived from a CS-habituation hypothesis.

Inhibition of delay. Since the notion of inhibition of delay has been invoked to explain the between-session weakening of conditioned suppression (e.g., Zielinski, 1966), perhaps it should also be considered as an account of the within-session decrements. To explain our results using the concept of inhibition of delay, one would have to assume that inhibition of delay increases over trials within a session only to be forgotten overnight. There is, it seems, some evidence for the forgetting of inhibition of delay (Hammond \& Maser, 1970); but, based on the work of Zielinski (1966), one would not expect inhibition of delay to occur early enough in the course of conditioning to generate the decrements observed here.

Disinhibition. A final account that we shall consider is one that is especially pertinent to conditioned suppression phenomena. Brimer and Kamin (1963) reported that rats whose pre-CS baselines had been depressed by prior unsignaled shocks tended to increase their response rates during the CS. It appeared, therefore, that the CS disinhibited baseline operant responding normally inhibited by previous shocks. Moreover, those rats whose baselines were the most severely inhibited tended to be the most disinhibited by CS presentations, as measured by high suppression ratios. ${ }^{4}$ Applied to our results, this notion of disinhibition suggests that shocks early in our sessions inhibited operant responding, which was then disinhibited by CSs occurring later.

There are several aspects of our results, however, that speak against a disinhibition account. In Conditions 4 and 6 , for example, pre-CS rates were moderately depressed after the first conditioning session; however, they remained relatively invariant across trials for Groups 62 and 135 in Condition 6 on Days 4 and 5 (Figure 2) and for Group $C$ in Condition 4 on Days 3,4 , and 5 . If disinhibition accounts for our rising suppression functions, then why does the disinhibition increase across trials? Why doesn't it occur equally on the first trial when the pre-CS baselines are equally inhibited? Finally, in the one-trial-a-day procedure (Condition 5), the pre-CS baseline was intentionally depressed for Group $\mathrm{H}$ but not for Group R (see Figure 2). Despite this, the CS did not seem to disinhibit responding for Group $\mathrm{H}$; in fact, the $H$ and $R$ groups seemed equally suppressed (Fig. ures 1 and 3). Perhaps, in Condition 5, the pre-CS baselines were not depressed enough. In a paper extending the work of Brimer and Kamin, Brimer
(1970) suggested that when extinction was the operation used to depress the baseline operant, the rate had to be in a range of 1 to 2 responses/min before disinhibition could be observed. However, in the conditioned suppression paper of Brimer and Kamin (1963), this was not true. Brimer and Kamin presented pre-CS and CS rates of seven representative subjects. For three of these subjects, the pre-CS and CS rates were 9-50, 76-136, and 59-118. Since the CS and pre-CS periods were 3 min long, the pre-CS rates of these animals were approximately 3,25 , and 20 responses/min, respectively. As Figure 2, Panel 5 shows, these pre-CS rates roughly bracket the mean rates of the subjects in our $\mathrm{H}$ condition on Days 4,5 , 6 , and 7 . We conclude, therefore, that the disinhibition notion does not seem to offer a compelling account of our results.

To summarize our findings and conclusions, we have found some conditions in which the functions describing the trial-by-trial acquisition of conditioned suppression are nonmonotonic. We do not believe that these nonmonotonicities reflect nonmonotonic changes in associative strength; we assume that learning increases monotonically and that our nonmonotonic performance functions reflect the growth of temporary opposing processes. Of these, shortterm refractory-like processes appear most promising. Our experiments were not designed to separate hypotheses, however, and offer little basis for selecting among them. The main contribution of our results, therefore, is not the settling of theoretical issues but rather the unequivocal demonstration, in the conditioned suppression procedure, of withinsession response decrements under continuous reinforcement. This demonstration should help to relate the suppression phenomenon to an older body of literature on Pavlovian conditioning and should remind us of a phenomenon that seems to have been neglected for some time. That this phenomenon has not been encountered previously by students of conditioned suppression may be due to a heavy reliance on a few "standardized" preparations in which response decrements apparently do not occur, and to our habit of blocking data over trials.

\section{REFERENCE NOTE}

1. Kamin, L. J. Personal communication, January 13, 1978.

\section{REFERENCES}

Annau, Z., \& Kamin, L. J. The conditioned emotional response as a function of intensity of the US. Journal of Comparative and Physiological Psychology, 1961, 54, 428-432.

Ayres, J. J. B., Mahoney, W. J., Proulx, D. T., \& Benedict, J. O. Backward conditioning as an extinction procedure. Learning and Motivation, 1976, 7, 368-381.

Brimer, C. J. Disinhibition of an operant response, Learning and Motivation, 1970, 1, 346-371. 
Brimer, C. J., \& Kamin, L. J. Disinhibition, habituation, sensitization, and the conditioned emotional response. Journal of Comparative and Physiological Psychology, 1963, 56, 508-516.

ChURCH, R. M. Response suppression. In B. A. Campbell \& R. M. Church (Eds.), Punishment and aversive behavior. New York: Appleton-Century-Crofts, 1969.

Epstein, S., \& BafM, R. Verbal hypothesis formulation during classical conditioning of the GSR. Journal of Experimental Psychology, 1971, 87, 187-197.

Estes, W. K., \& Skinner, B. F. Some quantitative properties of anxiety. Journal of Experimental Psychology, 1941, 29, 390-400.

Fleshler, M., \& Hoffman, H. S. A progression for generating variable interval schedules. Journal of the Experimental Analysis of Behavior, 1962, 5, 529-530.

HAMMOND, L. J., \& MASER, J. Forgetting and conditioned suppression: Role of a temporal discrimination. Journal of the Experimental Analysis of Behavior, 1970, 13, 333-338.

HendRY, D. P., \& VAN-Toller, C. Alleviation of conditioned suppression. Journal of Comparative and Physiological Psychol ogy, 1965, 59, 458-460.

Hilgard, E. R., \& Marquis, D. G. Acquisition, extinction, and retention of conditioned lid responses to light in dogs. Journal of Comparative and Physiological Psychology, 1935, 19. 29-58.

Hovland, C. I. "Inhibition of reinforcement" and phenomena of experimental extinction. Proceedings of the National Academy of Science, 1936, 22, 430-433.

Huld, C. L. Principles of behavior. New York: Appleton-CenturyCrofts, 1943.

KAMIL, A. C. The second-order conditioning of fear in rats. Psychonomic Science, 1968, 10, 99-100.

Kamin, L. J. Predictability, surprise, attention and conditioning. In B. A. Campbell \& R. M. Church (Eds.), Punishment and aversive behavior. New York: Appleton-Century-Crofts, 1969.

Kamin, L. J., \& GaIONI, S. J. Compound conditioned emotional response conditioning with differentially salient elements in rats. Journal of Comparative and Physiological Psychology, 1974, 87, 591-597.

KIMMEL, H. D., \& BuRns, R. A. Adaptational aspects of conditioning. In W. K. Estes (Ed.), Handbook of learning and cognitive processes (Vol. 2) Conditioning and behavior theory. Hillsdale, N.J: Erlbaum, 1975.

LiBBy, A. Two variables in the acquisition of depressant properties by a stimulus. Joumal of Experimental Psychology, 1951, 42, 100-107.

Millenson, J. R., \& Dent, J. G. Habituation of conditioned suppression. Quarterly Journal of Experimental Psychology, 1971, 23, 126-134.
Pavlov, I. P. Conditioned reflexes. New York: Dover, 1960.

PFAUTz, P. L., \& WAgner, A. R. Transient variations in responding to Pavlovian conditioned stimuli have implications for the mechanisms of "priming." Animal Learning \& Behavior, 1976, 4, 107-112.

Prokasy, W. F. Postasymptotic performance decrements during massed reinforcements. Psychological Bulletin, 1960, 57, 237-247.

Runquist, W. N., \& MurR, W. R. Intrasession decrements in the performance of the classically conditioned eyelid reflex. Journal of Experimental Psychology, 1965, 70, 520-525.

THEODOR, L. H. Conditioning to the elements, of a compound stimulus as a function of the intensity of one of the elements. Unpublished masters thesis, McMaster University, 1965.

ZIELINSKI, K. "Inhibition of delay" as a mechanism of the gradual weakening of the conditioned emotional response. Acta Biologiae Experimentalis, 1966, 26, 407-418.

\section{NOTES}

1. In all but Conditions 4 and 6 , the pre-CS period was equal in duration to the CS. In Condition 6, the pre-CS duration was $3 \mathrm{~min}$. In Condition 4, it ranged from 10 to $30 \mathrm{sec}$ depending on the intertrial interval.

2. These "p-values" are based on the results of $t$ tests using an error term derived from an analysis of variance.

3. After reading an earlier draft of this paper, L. J. Kamin (Note 1) stated that in an unpublished masters thesis, Theodor (1965) had found nonmonotonicities in Kamin's standard 2-h preparation. Theodor's Figure 2 shows pronounced nonmonotonicities when the CS was a 50-dB noise but not when it was an 80-dB noise.

4. There is a sense in which the correlation noted by Brimer and Kamin could have been artifactual. Even if every animal had made exactly the same number of responses during the CS, those animals with lower baselines would have had higher suppression ratios. The relationship between the depressed baseline and the high ratios may, then, merely have reflected the computational properties of the suppression ratio rather than a relation between the degree of inhibition and the degree of disinhibition. Nevertheless, we will take seriously in our discussion the notion that the amount of disinhibition should be proportional to the amount of prior inhibition.

(Received for publication April 14, 1978; revision accepted August 15, 1978.) 